Article

\title{
Do We Need Permission to Play in Public? The Design of Participation for Social Play Video Games at Play Parties and 'Alternative' Games Festivals
}

\author{
Lynn H. C. Love \\ School of Design and Informatics, Abertay University, Dundee, DD1 1HG, UK; E-Mail: I.parker@abertay.ac.uk
}

Submitted: 24 January 2018 | Accepted: 23 March 2018 | Published: 7 June 2018

\begin{abstract}
Play is fundamental to being Human. It helps to make sense of the self, to learn, to be creative and to relax. The advent of video games challenged traditional notions of play, introducing a single player experience to what had primarily been a communal social activity. As technology has developed, communal play has found both online and real-world spaces within video games. Online streaming, multiplayer games and built-in spectator modes within games underpin online communal play experiences, whilst 'alternative' games festivals, play parties and electronic sports, provide real world spaces for people to meet, play and exchange knowledge relating to both playing and making video games. This article reports the study of social play events which bring people together in the same space to explore video games making and playing. Expert interviews with curators, and event facilitators provides qualitative data from which design processes are formalised into a 'model of participation' of social play. Four key areas of balance are proposed as core considerations in supporting participation in event design. The study of these events also suggests that their design and fostering of participation has the potential to evoke cultural change in game making and playing practices.
\end{abstract}

\section{Keywords}

cultural intermediaries; cultural transformation; games; independent video games; social play events

Issue

This article is part of the issue "Games Matter? Current Theories and Studies on Digital Games", edited by Julia Kneer (Erasmus University Rotterdam, The Netherlands) and Ruud Jacobs (University of Twente, The Netherlands).

(C) 2018 by the author; licensee Cogitatio (Lisbon, Portugal). This article is licensed under a Creative Commons Attribution 4.0 International License (CC BY).

\section{Introduction}

Attending a social play games event, such as an "alternative" games festival like A MAZE. / Berlin or Feral Vector or an evening "play party" such as Games are for Everyone or Wild Rumpus can provide new gaming experiences for the attendee. Such experiences may be in the form of engagement in socially mediated narratives coconstructed by spectators and past players which sit ontop of gameplay, (Isbister, 2016), exposure to new types of games and game making practices or finding a sense of togetherness amongst a group of strangers through playing socially (Goddard, Garner, \& Jensen, 2016). Play parties and alternative games festivals seamlessly mix play with knowledge exchange, networking and socialising, providing attendees with a range of invitations to participate. Through participation in game making and playing, these events and their co-ordinators, as acknowl- edged within an interview with Lorenzo Pilia of Talk \& Play and A MAZE. / Berlin seek to engage not only with existing games communities but are also often interested in engaging with and promoting games making and playing practices to new communities. Thorsten S. Wiedemann of A MAZE. raises (within this research) that the programming of these events and the games they choose to showcase often differs in content, form or modes of interaction in comparison to events and games developed within commercial games making practices (Goddard \& Muscat, 2016), being more expressive and often more aligned to art practice in their form.

This research seeks to study the design of events which promote video games playing and development in co-located contexts and to identify the ways in which the event facilitators design for participation. These events rely upon attendance and participation to exist (culturally and financially) and thus, participation is positioned 
in this research as central to creating, maintaining and propagating social play events. Drawing from interviews with event facilitators and secondary research material publicly available about their work, these events will be studied in order to determine the needs of the communities who attend the events from the perspective of the event facilitator. The community needs will be used to inform the design and proposal of a model of participation in social play event design and to reflect upon the impact of these events on both the individual and on games making and playing culture.

The world of alternative games festivals and social play has had limited academic attention, despite the growing number of events which exist world-wide. The studies of play and games festivals which do exist aim to map the landscape of festivals in this field (Wood, 2016) and to study specific festival cases (Gavin, Kenobi, \& Connor, 2014; Parker, Whitson, \& Simon, 2017a). This study aims to contribute to this body of knowledge, focussing upon formalising design approaches, exposing practice and disseminating the knowledge drawn from a panel of experts whilst also considering the impact of these events upon society. The design of event and community participation has received significant academic attention within the fields of learning (Wenger, 1998; Wenger-Trayner, Fenton-O'Creevy, Hutchinson, Kubiak, \& Wenger-Trayner, 2015), business (Wenger, McDermott, \& Snyder, 2002), the arts (Simon, 2010; White \& Parker, in press) and creative industries (Brandt, 2006; Parker \& Galloway, 2017). Drawing from this landscape of theory around participation, the emerging model of practice identified within social play event design through this research can be evaluated, contextualised and better understood in terms of its impact upon individual and social participation.

This research focusses upon social play events which include alternative games festivals, play parties, and meet-ups. Electronic Sports, (eSports), events also make a significant contribution to social play design, however, these have been studied more extensively academically (see Hilvoorde \& Pot, 2016; Seo \& Jung, 2014) and sit beyond the scope of this research.

\subsection{Social Game Playing Communities}

The social play of video games exists in many forms, the most well-known of which targets the game making community, particularly established games companies, publishers and games related industries who share an interest in commercial games development. These large-scale events, (e.g. Game Developers Conference, or EGX), typically use traditional conference style approaches, mixing programmed talks, networking, and play sessions of video games in an exposition format. Commercial conferences tend to utilise a one-size-fits-all approach for the exposition of video games, providing a standard space for each exhibitor. In order to enhance their appeal to the commercial games making community, and as Holly
Gramazio, of Now Play This acknowledges within an interview, these conferences attempt to design spaces conducive to playing games and learning about games practices primarily for promotional purposes.

Independent games developers (indie developers), those who create games which typically sit outside of traditional commercial models in their content and production, are catered to by industrial conferences to some extent (Wood, 2016), however, in the last ten years, a range of alternative games festival have emerged, which focus upon diversity, creativity and experimental approaches to game development, promotion and publication. These festivals, like commercial conferences, make use of structured programming over a number of days, however, for Wiedemann, the spirit differs greatly, aiming to be more celebratory of game making and playing. The exhibition element tends to align more closely to artistic exhibition, fitting the presentation method to the work being shown. Alternative festivals also include practical workshops, inviting participation in the making of games in accessible sessions unlike those found at other games events.

There are also events which cater to more diverse audiences. Play Parties and meetup events invite participation from the general public, game developers (commercial and indie), games enthusiasts, academics and students. Alternative and commercial games festivals may cater to a range of these groups, however, often this is not to the same extent as found within meetup events. The play party or meetup tends to run for a few hours in one evening, happening multiple times in a year, focussing on community development or promotion of games as a form. The format varies from exhibiting games in a social setting to mixing exhibition with informal talks. The events also vary in presentation style from makeshift approaches which cobble together tables to facilitate games showcase through to polished curated exhibitions which use environmental design, reinterpretation of media and installation.

\section{Analysing the Landscape: The Interviewees}

To inform this research, six event facilitators were interviewed in semi-structured interviews lasting between one and two hours in length. The facilitators were selected for interview due to their experience of designing events which promote social play and game making practices. The events studied vary from well-established to those in their first year to provide insight into the range of challenges events can face at different stages in their development. Table 1 outlines each event studied within this research.

The interviews focussed upon four key themes: the event and practice of the event producer, exploration of the role of play within festival design, considerations of community in festival design and reflections upon the impact of festival practice upon the audience, culture and society. The data gathered from interviews and 
Table 1. Overview of the events studied within this research including interviewee names, event descriptions, activity types, and attendee numbers.

\begin{tabular}{lll}
\hline Event and interviewee & Event Description & Event Classification and Activities \\
\hline A MAZE. / Berlin & $\begin{array}{l}\text { Four day “International Games and } \\
\text { Playful Media Festival” (A MAZE. GmbH, }\end{array}$ & Festival \\
2008-present & 2017) occurs annually. & $\begin{array}{l}\text { Curated and open exhibition, workshops } \\
\text { (making \& playing), curated talks, social spaces, } \\
\text { parties, awards. }\end{array}$ \\
$\begin{array}{l}\text { Thorsten S. Wiedemann } \\
\text { and Lorenzo Pilia }\end{array}$ & & palial
\end{tabular}

\begin{tabular}{ll}
\hline Arcadia & One day "celebration of independent \\
$2017-p r e s e n t$ & games" (Arcadia, 2017) occurs annually.
\end{tabular}

Malath Abbas

Curated exhibition, workshops (making \& playing), curated talks, social spaces, parties.

\begin{tabular}{|c|c|c|}
\hline $\begin{array}{l}\text { Feral Vector } \\
\text { 2012-present } \\
\text { David Hayward }\end{array}$ & $\begin{array}{l}\text { Three day "festival about making games } \\
\text { and gamelike things". (YMPT Ltd, 2017) } \\
\text { occurs annually. }\end{array}$ & $\begin{array}{l}\text { Festival } \\
\text { Exhibition, workshops (making \& playing), } \\
\text { curated talks, social spaces. }\end{array}$ \\
\hline $\begin{array}{l}\text { Games are for } \\
\text { Everyone (GAFE) } \\
\text { 2015-present } \\
\text { Andrew Dyce and } \\
\text { Craig Fairweather }\end{array}$ & $\begin{array}{l}\text { "A night of fantastic, raucous, } \\
\text { beautiful games, mixed with drinks, } \\
\text { music, and wonderful people" occurs } \\
2-3 \text { times per year (We Throw } \\
\text { Switches, 2017) }\end{array}$ & $\begin{array}{l}\text { Play Party } \\
\text { Curated exhibition, social spaces, parties, } \\
\text { commissioning new work. }\end{array}$ \\
\hline $\begin{array}{l}\text { Now Play This } \\
\text { 2015-present } \\
\text { Holly Gramazio }\end{array}$ & $\begin{array}{l}\text { Three day "festival of experimental } \\
\text { game design" (Now Play This, 2017) } \\
\text { occurs annually. }\end{array}$ & $\begin{array}{l}\text { Festival } \\
\text { Curated Exhibition, workshops (making \& playing), } \\
\text { Curated talks, commissioning new work. }\end{array}$ \\
\hline $\begin{array}{l}\text { Talk \& Play } \\
\text { 2013-present } \\
\text { Lorenzo Pilia }\end{array}$ & $\begin{array}{l}\text { A bi-monthly event which "provides } \\
\text { the opportunity to game enthusiasts, } \\
\text { players and makers to meet and } \\
\text { exchange knowledge in a friendly, } \\
\text { relaxed and safe environment". } \\
\text { (BerlinGameScene.com, 2018) }\end{array}$ & $\begin{array}{l}\text { Meet-up } \\
\text { Open exhibition, curated talks, } \\
\text { audience shout-outs, social spaces. }\end{array}$ \\
\hline
\end{tabular}

secondary sources underwent thematic analysis utilising the six-step process (Braun \& Clarke, 2006). Thematic codes were drawn inductively from the interviewee responses in order to ensure that design concepts came from the data rather than being shaped by researcher perspectives (Saldaña, 2015). Data sets were compared per theme and were used to inform the design of the relationships presented within the model of participation which forms the core findings of this research (Braun \& Clarke, 2006).

\section{Needs of Games Communities}

The interviews demonstrate that within their design process, facilitators consider the specific needs of the diverse communities who attend their event. Each specific attendee grouping presents issues, in relation to their own needs, and also in relation to their interactions with the needs of other communities at the event. Facilitators use design approaches to mitigate issues specific to and across each grouping. In order to better understand the tensions within and across audience groupings, attendees can be broadly categorised as games and professional or general communities. These two groupings present competing interests which the facilitator must manage to support and promote participation in their event. Detailed overviews of the audience profiles for each event within the research is provided in Table 2.

Analysis of the interviews presented four key community needs that facilitators consider in facilitating participation: supporting attendee confidence, legitimising games as a social practice, providing spaces to support diverse interests, and managing competing interests. These key community needs were identified by facilitators across the data set and therefore are seen to be transferable considerations for participation design regardless of the specific event at hand. The considerations can be defined as follows:

- Catering to and supporting the confidence levels of attendees is a common consideration for facilitators, regardless of community. Confidence levels 
Table 2. Overview of audiences for each event.

\begin{tabular}{|c|c|c|c|}
\hline Event & Attendees (2017) & Games \& Professional Communities & General Communities \\
\hline A MAZE. / Berlin & 5,500 visitors & $\begin{array}{l}\text { Game developers * } \\
\text { Publishers } \\
\text { Practitioners from other fields }\end{array}$ & $\begin{array}{l}\text { Students } \\
\text { Games enthusiasts } \\
\text { General public }\end{array}$ \\
\hline Arcadia & 200 people & Game developers* & $\begin{array}{l}\text { Students* } \\
\text { Games enthusiasts } \\
\text { General public }\end{array}$ \\
\hline Feral Vector & 200 people & $\begin{array}{l}\text { Game developers* } \\
\text { Practitioners from other fields }\end{array}$ & $\begin{array}{l}\text { Students } \\
\text { Games enthusiasts }\end{array}$ \\
\hline Games are for Everyone & 500 people & $\begin{array}{l}\text { Game developers* } \\
\text { Practitioners from other fields* }\end{array}$ & $\begin{array}{l}\text { Students* } \\
\text { Games enthusiasts* } \\
\text { General public* }\end{array}$ \\
\hline Now Play This & 2,100 people & Game developers & $\begin{array}{l}\text { Students } \\
\text { Games enthusiasts } \\
\text { General public* }\end{array}$ \\
\hline Talk and Play & 150-200 people & $\begin{array}{l}\text { Game developers* } \\
\text { Practitioners from other fields }\end{array}$ & $\begin{array}{l}\text { Students } \\
\text { Games enthusiasts* } \\
\text { General public }\end{array}$ \\
\hline
\end{tabular}

Notes: ${ }^{*}$ indicates the groupings which are the majority at each event.

seem directly connected to the amount of knowledge or experience an individual has around an event and whether they are attending in a group or alone;

- Preconceptions and negative stigma around games is a significant issue for facilitators in relation to general community participation. Outside game making and playing circles, games are often still associated with negative connotations about their content, the people who play them and who make them. These connotations act as barriers to entry for expanding participation;

- Social play events present models of value in the work they select and promote to both professional and general games audiences. Such curation, however, can also be seen as gatekeeping, creating tensions within professional games communities in terms of their place within a curated 'image' of games development. The systems of value promoted by such events can enhance or limit participation by professional communities;

- Social play events tend to develop a 'core community' of regular attendees as they become more established. The core community differs across each event within this research, however, a distinct tension is apparent between the two different types of community identified: the professional and the general community. The needs and interests of these groups differ in complexity, accessibility, and participation levels. Accommodating such diverse needs to support participation presents significant programming challenges.
These four community needs provide valuable insight into the challenges faced by facilitators in event design. Further interrogation of interview data, using each of these community needs as analytical lenses provided a basis for the creation of a 'model of participation design' (Table 3). This model details the ways in which expert practitioners design their events in order to facilitate participation by their target audiences. The model of participation design proposes that social play event design for participation requires the balance of a series of competing interests of diverse communities.

Table 3. Model of participation design.

Comfort and Discomfort

(confidence to expand perspectives)

Niche and Mainstream

(legitimacy to expand audiences)

Curation and Gatekeeping

(diversity in space provision for participation)

Insiders and Outsiders

(Scaffolding to support community expansion)

Notes: The underpinning community needs are presented in italics.

The model is informed not only by the design techniques identified by the practitioners themselves during discussion, but also from consideration of specific examples of practice evident within the interview data set and within promotional material relating to each of the events within the study. Common themes in practice across the data set were identified and provided a basis 
for the formation of the model. Further analysis was then undertaken to identify outliers and issues specific to individual events in order to recognise the diversity of audiences not only within each event but also across all of the events which make up the data set. The final model for participation design thus presents common practices amongst practitioners whilst also acknowledging innovative approaches specific to individual events. These outliers are presented as examples of best practice that are designed specifically for the community needs of a particular event. Inclusion of best practice examples in the design of the model of participation embeds, within the model, the promotion that a one-size-fits-all approach cannot be used to enhance participation and instead that facilitators must design for and innovate for the needs of their community, working with their community to enhance participation.

The first set of competing interests identified within the model are comfort and discomfort which relate to building a space and facilitating events which allows confidence to grow within a diverse community. Confidence and comfort are integral to laying a foundation from which the facilitator can support and disrupt conventional practices to achieve transformation through experimentation and playfulness in participation. Secondly, the niche and mainstream consideration acknowledges the difficult positioning of games and play more broadly in western culture and identifies approaches utilised by facilitators to promote legitimacy around video games in social contexts to enhance participation and diversify audiences.

Curation and gatekeeping, the third set of competing interests, recognises the event facilitator as a cultural intermediary, promoting value through their selection (and thus filtering) of media for their events. Interview discussions reveal that no one event can address tensions presented by the exclusive nature of promotion of value and thus, that social play events rely upon the proliferation of partner events with different aims, values and interests in order to support community expansion and develop participation in videogame playing and making practices. The fourth and final set of competing interests, insiders and outsiders, reflects the specialist nature of the communities which gather around videogames and explores the ways in which newcomers to the events can be supported by the facilitators or, by the community, through designed scaffolding in the event, to transition into full members of the community. The following section discusses each of the four competing interests proposed within the model in depth, providing insight into the approaches used by facilitators (with specific examples) to maintain (or otherwise) a balance to foster participation.

\subsection{Comfort and Discomfort}

Central to fostering participation in an event is the creation of a space where people feel comfortable. Intervie- wees widely recognise that if people feel comfortable, they are more likely to participate. Pilia believes that considering the first impressions of an event, both in its promotional text and upon first entering the venue (including consideration of its atmosphere and facilities) are basic factors which can enhance attendee comfort levels inviting them to firstly attend and secondly to be open to the possibilities presented by the event. This view is also supported by Andrew Dyce and Craig Fairweather of Games are For Everyone and Gramazio. Play and playfulness are core design techniques used to build on first impressions and whether accessed by the attendee through active interaction with a game, talk or workshop or through being part of the audience, can help to unlock the potential of games as a form (Sharp, 2015). In attempting to make people comfortable at a social play event, it is integral that facilitators provide attendees with every opportunity to see potential in games and play for themselves. Facilitators, therefore, design different "ecologies of participation" (Fischer, 2011), a series of invitations which invite different levels of participation to suit the varying confidence levels of attendees. Gramazio, for example, provides print works for contemplation and creates spaces for spectatorship (Figure 1), whilst Wiedemann and Pilia aim to provide a programme with space for playful attendee improvisation and contribution. These are a few approaches which provide a continuum of participation within the programme of an event within which attendees can be active agents in selecting activities to suit their needs, comfort and confidence levels enhancing their potential for participation.

Comfort and confidence fosters attendee participation at a level which suits their needs, whereas discomfort can act as a barrier to participation. In seeking to promote games as a cultural form, many of these events aim to redefine attendee preconceptions around games; such challenges to individual value systems can cause discomfort. Play, however, inherently contains transformative potential (Bogost, 2008) which can be fostered by event facilitators to aid shifts of perspective whilst disarming discomfort. Transformative play can have many effects for the player including shifting their thinking, behaviour, and social relationships with others (both players and non-players) (Salen \& Zimmerman, 2004). Play or playfulness in event design, such as providing ecologies of participation and supporting attendee agency, affords the potential to transform attendee perspectives around game playing and making practice.

David Hayward acknowledges this potential for transformation suggesting that discomfort can achieve similar effects. He believes physically relocating to attend an event in another place (potential for discomfort) can free individuals from the social limitations faced everyday providing them with a space to experiment with aspects of personal identity, behaviour or ways of thinking. Such experimentation through participation can transform their thinking both within and beyond the event. Shusterman (2012, p. 29) promotes the social element 


\section{COGITATIO}

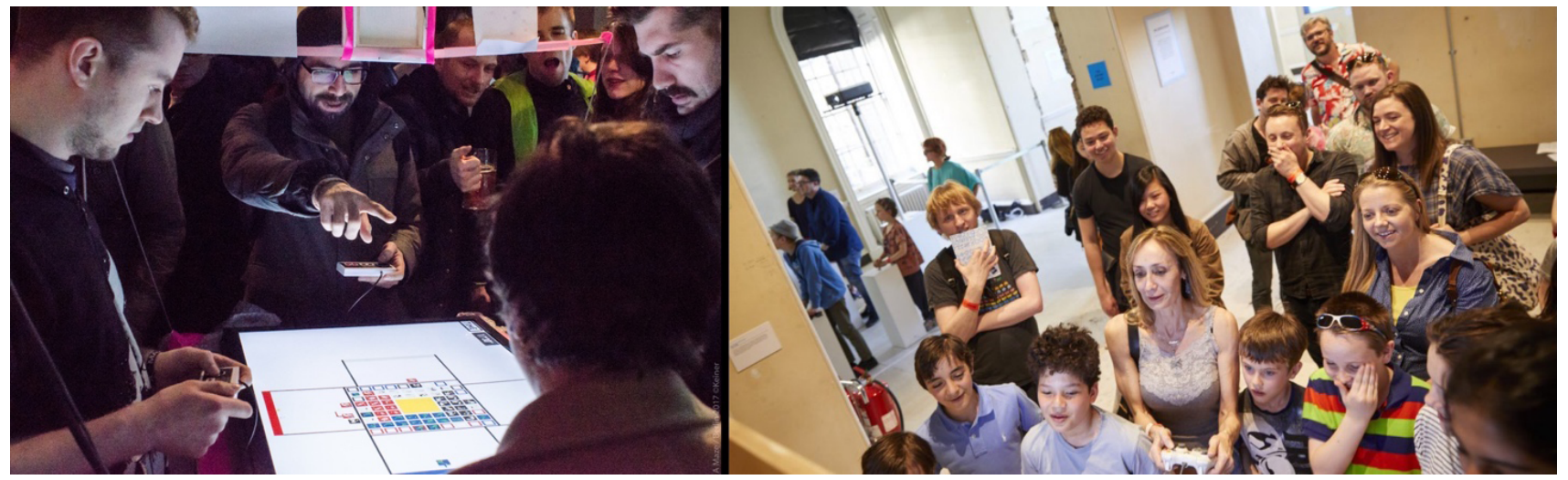

Figure 1. Many events design spaces which allow play and spectatorship to co-exist, supporting ecologies of participation. These include A MAZE. / Berlin, left showcasing SIHEYU4N (We Are Müesli \& Koning, 2015). Image copyright by Jens Keiner (2017, reprinted with permission). Right showcasing Now Play This. Image copyright by Ben Peter Catchpole (2017, reprinted with permission). Games Are for Everyone and A MAZE. / Johannesburg.

of experimentation believing that "the aesthetic experience of collaborative creation, and even the cognitive gains from exploring new practices that provoke new sensations, spur new energies and attitudes, and thus probe one's current limits and perhaps transcend them to transform the self". The potential for individual transformation, therefore, can be driven not only by programming a continuum of participation but also by the approaches of the individual motivated by event affordances.

Games and play have inherent links to culture (Caillois, 1958/1961; Huizinga, 1944/1949), often providing either a reflection of culture or the potential for transformation of culture (Salen \& Zimmerman, 2004). The framing of games, play and playfulness more broadly, in an event context is key to unlocking its transformative potential (Salen \& Zimmerman, 2004). Events which seek to influence the culture of games playing and making practice, therefore, must consider programming to explore cultural concerns whilst also fostering participation through a balance of comfort and discomfort to create conditions to unlock the transformative potential embedded in play.

\subsection{Niche and Mainstream}

Social play events which promote games playing and making practices are niche in nature and tend to appeal to specific audiences. Videogames as a form, have a broadly negative reputation in mainstream culture, often attracting demonizing headlines in the media (i.e. Manager, 2015; The Telegraph, 2012). News outlets are a form of cultural intermediary, organisations which mediate between producers and consumers (Hesmondhalgh, 2006) providing frameworks for understanding cultural meaning (Venkatesh \& Meamber, 2006) and legitimacy (Smith Maguire \& Matthews, 2012). Negative notions of video games in mainstream media lead to a misunderstanding of video games as a form, promoting their negative qualities and negating their potential cultural and societal value. The stigma surrounding video games in mainstream media and their lack of recognised value in Western culture (Bogost, 2008) presents issues to the expansion of participation in social play events.

To disarm the stigma around video games, their creators and their players, event facilitators including Dyce and Fairweather use accepted social settings (such as a bar or club) to try to "normalise" video games for mainstream audiences. Social spaces are embraced by society for other forms of media (i.e. cinemas, libraries, theatres) therefore, templates exist for legitimate video games social space design. Using the legitimising qualities of such spaces, however, requires reconsideration of models of presentation of games in a social context. Arcades provide a historical model for the presentation of games in a social context, a model adopted by the commercial games conferences one-size-fits-all approach to exposition. This model limits social potential, minimising space for spectatorship and providing difficulties in participating due to high attendee numbers. Games are naturally a form of social technology which provide a system to foster interactions through play (Flanagan, 2009) however, as seen with conferences, arcades, galleries and museums (White \& Parker, in press) their social potential can be expanded or limited by event design.

Facilitators design to enhance social potential of games through careful curation of games with affordances to suit social settings (i.e. multiplayer or physical games) (Goddard \& Muscat, 2016). Dyce and Fairweather, through simplification of control schemes and designed presentation of games aim to remove boundaries and enhance participative draw (Figure 2). Such re-interpretation of games can enhance their social potential and embed them legitimately within their social context. Wiedemann believes video games will always remain a niche interest, however, the promotion of their value, beyond that seen within mainstream media may enhance of participation and aid the redefinition of games culture. 


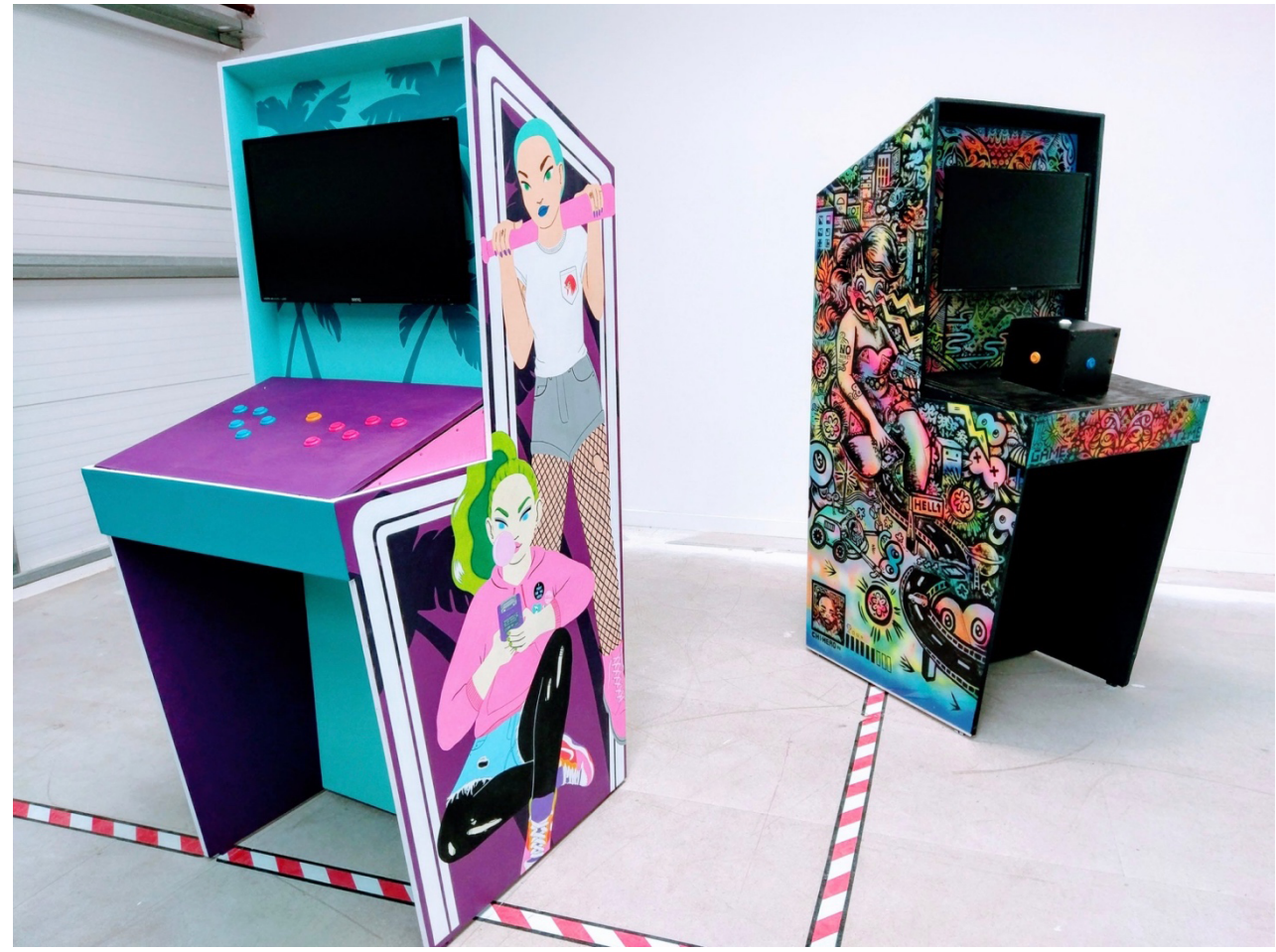

Figure 2. Games are for Everyone uses arcade cabinets as artworks in their own right which also house experimental games, providing participative draw and supporting ecologies of participation for players, spectators and those who wish to 'view' the cabinets. Image copyright by We Throw Switches (2017, reprinted with permission).

\subsection{Curation and Gatekeeping}

Events which showcase games culture typically involve a selection process to determine work which is deemed suitable for the event. An open call for submissions to the programme (i.e. A MAZE. GmbH, 2017; Now Play This, 2017) or invitation to individuals to contribute to the event based upon the facilitator's knowledge of their work (as acknowledged by Pilia in organisation of games showcases at Talk \& Play and Wiedemann in programming the A MAZE. / Berlin exhibition space) typically provides a wealth of material, from which the facilitator (or an expert panel) can make selections to create the event programme.

Selection positions the facilitator as curator, associating value and legitimacy to the work they choose over that they reject (Balzer, 2014). The facilitator-curator is again a form of cultural intermediary, applying their expertise within their field to frame material as having value (Smith Maguire \& Matthews, 2012). Parker et al. (2017a) position Indie Megabooth, a curated independent games showcase, as a cultural intermediary, recognising its role in promoting a cultural image of indie games propagating the "popular discourse around 'indieness' in the game industry and gaming culture". They propose that Indie Megabooth along with other key cultural intermediaries act as "curator-gatekeeper" in the selection and promotion of indie games.

In designing for participation, whether for game makers or players, facilitators must consider the balance be- tween curation and gatekeeping. These two very similar concepts of value promotion can be differentiated by considering the facilitator's motivation. Gramazio believes curation opens the opportunity for the event to build a narrative around a series of selected media and speakers (Dernie, 2006) whilst Dyce and Fairweather feel they can communicate messages which perhaps compete with those promoted in mainstream media. Gatekeeping on the other hand, particularly when it relates to the promotion of a particular image of a community (Parker et al., 2017a), can be seen as defining the general audiences' "social reality" (Shoemaker \& Vos, 2009, p. 3) of that community. In turn, this can exclude and alienate portions of the game making community who are not deemed to fit the image or values being promoted, leading to divisions and friction (Parker et al., 2017a).

The balance of curation and gatekeeping lies perhaps in transparency and diversity. With gatekeeping, "issues and events that are not covered are absent from the world view of most audience members. People cannot know about what the media fail to tell them" (Shoemaker \& Vos, 2009, p. 4). Cultural intermediaries shape audiences' experiences of game making and playing culture through their selection of material and narrative creation. The motivations for facilitating an event and a facilitators own sense of cultural value can shape their curatorial approaches (Balzer, 2014). The interviews revealed several motivations for event facilitation including developing games culture, building communities, redefining social play conventions, and inspiring talent. Trans- 
parency around the motivation of an event throughout its promotional material and its operation provides attendees with clarity helping to manage their expectations, potentially limiting friction. Additionally, the diverse motivations for event facilitation creates a landscape of unique events, each with a particular focus and approach to potentially suit different group interests (Figure 3). Taste is a socially formed concept which has an organising feature often grouping people together with shared interests (Smith Maguire, 2015) thus the greater the diversity of social play events that exist within the landscape, the more likely that the shared tastes of diverse communities will be catered to by at least one event, potentially avoiding alienation. Each social play event can be seen to co-exist in an ecosystem, supporting the participation and development of its own communities, whilst also expanding the ecology of participation across all social play events by providing unique opportunities which cater to diverse audiences.

\subsection{Insiders and Outsiders}

Dyce and Fairweather, Pilia, and Wiedemann, acknowledge that social play events are interested in diversifying audiences to address issues of the niche and mainstream and to refresh the practice of the games making community through inviting, inspiring and developing new perspectives, talent and voices. The 'core community' of an event can be positioned as 'insiders' who have expertise, social bonds and previous knowledge of the event, forming a community of practice (a group of individuals who form shared values, beliefs and practices through shared interest of a subject; Wenger, 1998). This core community may seem closed to 'outsiders', newcomers to the event, perhaps through appearing as Hayward acknowledges in relation to his experience, an intimidating 'clique' (Wenger et al., 2002) or as identified by Pilia, through boundaries presented by specialist knowledge and expertise (Wenger-Trayner et al., 2015).

Balancing the needs and interests of professional and general communities in programme design can be difficult. Professional communities tend to be interested in opportunities to enhance their specialist skills, connect with peers, potential collaborators and publishers whereas general communities tend to be interested in finding access points into game making and playing practices. Pilia believes that it is not possible to suit the interests of everyone, and specialist communities may feel alienated or disenfranchised by general programming for a broader audience.

The social play event, in expanding participation, can be understood as bringing together several communities of practice (each with competing sets of shared experiences, interests and values), which sit across the interdisciplinary landscape of practice (Wenger, 1998). 'Competence' is a socially held quality, which helps individuals to operate within and across communities of practice (Wenger-Trayner \& Wenger-Trayner, 2015, p. 13). Within the game making community, competence may be seen as, for example, familiarity with game engines, artistic techniques or design approaches. Should an individual seek to enter a new community of practice, their competences will either shift to "reflect the competence of the community" or will challenge and potentially transform the "regime of competence" of the community (WengerTrayner \& Wenger-Trayner, 2015, p. 14). It is difficult for a general community member to develop specialist expertise upon their first interaction with the professional games community, however brief, initial interaction will allow familiarity to develop and may encourage individuals to continue their learning beyond the event, eventually developing competencies that allow them to become games practitioners. The professional community can benefit from the expertise of general community members as they can draw from their knowledge and experience of participation in other specialist communities of practice, which may indeed challenge and perhaps enhance the practice of the game making community (Wenger-Trayner \& Wenger-Trayner, 2015).

It is not possible to design a community of practice (Wenger, 1998), therefore, the facilitator, whether starting a new event or building from an established community, can only design conditions within which a community may drive its own development (Parker \& Gal-

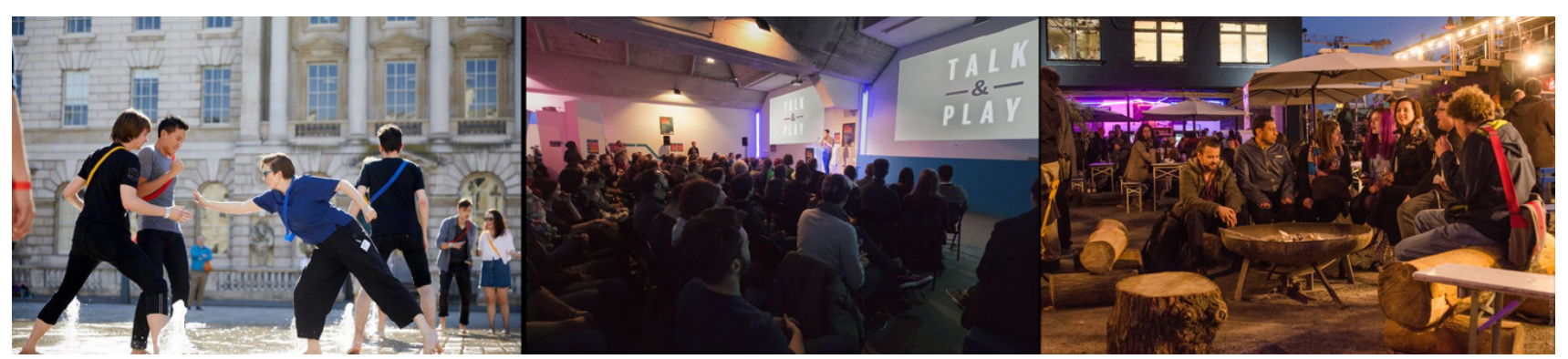

Figure 3. Social play events create unique experiences around playing and making practices as evident with through: (a) the physical play of Carpe Diem (Lun, 2017) at Now Play This-Copyright by Ben Peter Catchpole (2017, reprinted with permission); (b) the consideration of speaker and topic diversity at Talk \& Play-Copyright by Julian Dasgupta (2017, reprinted with permission); (c) and the informal social spaces provided by A MAZE. / Berlin-Copyright by Jens Keiner (2017, reprinted with permission). 
loway, 2017). Designing for participation is proposed as scaffolding that facilitators can provide to support transformational shifts and expansion of communities. Dyce and Fairweather, Hayward and Pilia all recognise that the exchange of knowledge, experiences and competencies can naturally emerge from the communities themselves given the creation of comfort, careful management of the niche and appropriate curation of an event.

The scaffolding provided to support transition from 'outsiders' to 'insiders' in a community by facilitators includes, for Pilia, programming accessible content, supporting knowledge exchange and for Malath Abbas, Pilia, and Wiedemann providing attendees with opportunities to present, participate and actively create the event themselves. Pilia also believes that the provision of online spaces for the community to continue engaging beyond each event is integral to participation and on-going involvement. Dyce and Fairweather believe that it is not possible to fully integrate into a community by attending an event only once; repeated attendance is needed to allow an individual to develop competencies to transition from "outsider" to "insider". This idea is also echoed by Pilia.

\section{Analysing the Model: Facilitation Impact and Challenges}

The model of participation provides an overview of community driven concerns for event facilitation. The model can be used by facilitators to evaluate their design approaches prior to or in the development of event facilitation. Each event, however, must balance the different factors in the model in an appropriate way for their specific community and event motivation as can be seen by the diverse approaches used by facilitators in this research.

The model and methods of design used by facilitators also provides insight into the impact and value of these events which cannot be measured in monetary terms but rather is recognised in the impact upon individual (local community) and also society (see Table 4).

Facilitators face significant issues other than those presented within the model. Each event within this research relies upon an individual to occur which, for some, causes significant personal cost on stress levels, morale and financial sustainability. Similar connections between an event and an individual have been recognised in other studies of social play events (see Parker et al., 2017a). It seems that the individual, their reputation and networks are core to creating appeal, programme diversity, and motivating the recurrence of events. In turn, the individual is able to shape the event programme through their own curatorial voice contributing to event diversification (niche and mainstream issues) whilst potentially aggravating issues around curation and gatekeeping (however, Wiedemann acknowledges the importance of working with a team to avoid unconscious bias or for Hayward, what could be seen as a 'personality cult').

The publisher and commercial games community are under-represented within this research, with few interviewees providing insight into the design for involvement of these audiences. The experimental games and practices showcased at these events exist out with accepted commercial frameworks making it difficult to explain their value to commercially focused entities. Throughout the interviews, explaining the positioning of games as valuable cultural artefacts was a constant issue. Half of interviewees have previously secured some public and/or commercial funding to support their events, however, overall, they rely upon in-kind support, volunteers, and ticket sale income. Social play events exist in flux from year to year, struggling for sustainability due to such issues with funding and promotion of value to potential stakeholders.

Social play events have the potential to lead cultural and social transformation around video game making and playing practice as demonstrated by the model of participation, however, many facilitators recognise that these new forms of cultural intermediation are lacking in models of practice which can aid the creation of sustainable models independent of the individual. Wiedemann suggests that institutionalisation of events into independent organisations run by a team or by a series of lead facilitators, each for a fixed term, is a possible solution to personal attachment, stress and cost of event facilitation. It may be, however, that as Smith, Maguire and Matthews (2012, p. 5) suggest, "the personal is necessarily professional" in cultural intermediation and that

Table 4. An overview of the impact of social play events locally and more widely as described by the model of participation. Impact of social play events on individual and local community

- Building of confidence and new relationships with game playing and making practices through agency in participative levels

- Inspiring, expanding and motivating communities through programming, agency and enhancing social potential - Providing spaces for experimentation, playfulness and potentially individual transformation

Impact of social play events on industry and society

- Designing spaces which enhance the potential for cultural transformation of game making and playing practice

- Redefining the image of games socially and culturally to general and professional audiences

- Defining ways of positioning games authentically in social contexts to enhance their legitimacy

- Collaborative formation of culture through support, diversification and propagation of communities of practice 
successful event delivery relies wholly upon the personal effort and motivation of these individuals, their reputation and networks. Creating supporting infrastructure and models for institutionalising these events may propagate their growth but may also negatively impact their legitimacy, appeal and programming.

\section{Conclusion and Future Work}

The facilitation of participation in social play events can be seen to rely upon the balance of four key factors: Comfort and discomfort; niche and mainstream; curation and gatekeeping; and insiders and outsiders. The model presented within this article seeks to formalise the design considerations for social play participative event facilitation, as informed by analysis of expert facilitators understanding of the needs of their communities. This model is theoretical, formed through discussion with expert practitioners and secondary source analysis. It aims to combine common sense considerations with design practices in order to facilitate participation, foster agency and potentially lead to transformation for attendees, and for game making and playing culture as whole. The model aims to summarise complex considerations of events which cater to a range of audiences across diverse environmental contexts. It does not provide a one-size-fitsall model for the design of participation and if applied, needs to be tailored to each new event. It is also important to acknowledge that the model is not exhaustive and could benefit from expansion of the data to consider the design processes of further social play events and practical application as a design approach in order to fully test its robustness.

Social play events are emerging forms of cultural and social practice which exist within an ecosystem and their facilitators could benefit from opportunities to share their experiences and insights with one another more formally than at present, in order to help explore sustainability and the development of potential models of infrastructure to support event delivery. Academia could play a significant role in facilitating, formalising and revealing these practices, and indeed, Concordia University has taken the lead in such knowledge sharing, hosting an "Indie Interfaces Symposium" in 2017 (Parker et al., 2017b).

The facilitation of co-located social play can clearly make significant contributions to individual attendees, games communities and to society beyond games playing and making cultures. These cultural intermediaries are at the forefront of a new movement in socialtechnological-artistic practice and, driven by their interests in invoking transformation and promoting the form, are leading the way to new ways of making, playing and living with video games.

\section{Acknowledgements}

The author would like to thank the facilitators who contributed to this research for their input, insight, hon- esty and generosity. The author also wishes to thank Professor Gregor White for his invaluable support of this research.

\section{Conflict of Interests}

The author was a volunteer at Arcadia 2017 and delivered a workshop at this event.

\section{References}

A MAZE. GmbH. (2017). A MAZE/Berlin 2018. Retrieved from http://amaze-berlin.de

Arcadia. (2017). Arcadia: A celebration of independent games. Retrieved from https://www.arcadia dundee.com

Balzer, D. (2014). Curationism: How curating took over the art world and everything else. London: Pluto Press.

BerlinGameScene.com. (2018). Talk \& play. BerlinGame Scene.com. Retrieved from http://berlingamescene. com/talkandplay

Bogost, I. (2008). The rhetoric of video games. In K. Salen (Eds.), The ecology of games: Connecting youth, games, and learning (pp. 117-140). Cambridge, MA: The MIT Press.

Brandt, E. (2006). Designing exploratory design games: A framework for participation in participatory design? In G. Jacucci \& F. Kensing (Eds.), Proceedings of the ninth conference on participatory design: Expanding boundaries in design (pp. 57-66). Trento: ACM.

Braun, V., \& Clarke, V. (2006). Using thematic analysis in psychology. Qualitative Research in Psychology, 3(2), 77-101.

Caillois, R. (1961). Man, play and games. (M. Barash, Trans.). Chicago, IL: University of Illinois Press. (Original work published 1958)

Dernie, D. (2006). Exhibition design. New York, NY: W. W. Norton \& Company.

Fischer, G. (2011). Understanding, fostering, and supporting cultures of participation. Interactions, 18(3), 42-53.

Flanagan, M. (2009). Critical play: Radical game design. London: MIT Press.

Gavin, J., Kenobi, B., \& Connor, A. M. (2014). Social play spaces for active community engagement. In K. Blackmore, K. Nesbitt, \& S.P. Smith (Eds.), Proceedings of the 2014 conference on interactive entertainment (pp. 1-5). Newcastle: ACM.

Goddard, W., Garner, J., \& Jensen, M. M. (2016). Designing for social play in co-located mobile games. In Proceedings of the Australasian computer science week multiconference (ACSW '16). Canberra: ACM.

Goddard, W., \& Muscat, A. (2016). Designing unconventional use of conventional displays in games: Some assembly required. In S. Bjork, C. O'Donnell, \& R. Bidarra (Eds.), Proceedings of 1st international joint conference of DiGRA and FDG (pp. 1-15). Retrieved from http://www.digra.org/digital-library/ 
publications/designing-unconventional-use-of-conven tional-displays-in-games-some-assembly-required

Hesmondhalgh, D. (2006). Bourdieu, the media and cultural production. Media, Culture \& Society, 28(2), 211-231.

Hilvoorde, I. V., \& Pot, N. (2016). Embodiment and fundamental motor skills in eSports. Sport, Ethics and Philosophy, 10(1), 14-27.

Huizinga, J. (1949). Homo ludens: A study of the playelement in culture. London: Routledge. (Original work published 1944)

Isbister, K. (2016). How games move us: Emotion by design. London: The MIT Press.

Manager, W. (2015, May 20). Are video games harming our kids? Study warns they lead to neglect of parts of brain. The Mirror. Retrieved from http://www. mirror.co.uk/lifestyle/staying-in/video-games/videogames-harming-kids-study-5732893

Lun, L. S. (2017). Carpe diem. [Physical game]. Melbourne: Playreactive.

Now Play This. (2017). Now Play This. Retrieved from http://nowplaythis.net

Parker, F., Whitson, J. R., \& Simon, B. (2017a). Megabooth: The cultural intermediation of indie games. New Media \& Society. doi:10.1177/ 1461444817711403

Parker, F., Whitson, J. R., \& Simon, B. (2017b). Indie interfaces. Retrieved from https://www.indieinterfaces. com/conference

Parker, L., \& Galloway, D. (2017). Creative communities: Shaping process through performance and play. Transactions of the Digital Games Research Association (ToDiGRA), 3(2), 57-87.

Saldaña, J. (2015). The coding manual for qualitative researchers. (3rd ed.). London: SAGE.

Salen, K., \& Zimmerman, E. (2004). Rules of play: Game design fundamentals. London: MIT Press.

Seo, Y., \& Jung, S. (2014). Beyond solitary play in computer games: The social practices of eSports. Journal of Consumer Culture, 16(3), 635-655.

Sharp, J. (2015). Works of game: On the aesthetics of games and art. Cambridge, MA: The MIT Press.

Shoemaker, P. J., \& Vos, T. (2009). Gatekeeping theory. New York, NY: Routledge.

Shusterman, R. (2012). Aesthetic transactions: Pragmatist philosophy through art and life [Exhibition catalogue]. Paris: Michel Journiac Gallery. Retrieved from http://aesthetictransactions.webs.com

Simon, N. (2010). The participatory museum. Santa Cruz, CA: Museum 20.
Smith Maguire, J. (2015). Bourdieu on cultural intermediaries. In J. Smith Maguire \& J. Matthews (Eds.), The cultural intermediaries reader (pp. 15-24). London: SAGE.

Smith Maguire, J., \& Matthews, J. (2012). Are we all cultural intermediaries now? An introduction to cultural intermediaries in context. European Journal of Cultural Studies, 15(5), 551-556.

Venkatesh, A., \& Meamber, L. A. (2006). Arts and aesthetics: Marketing and cultural production. Marketing Theory, 6(1), 11-39.

The Telegraph. (2012, October 8). Violent video games make teenagers more aggressive, study finds. The Telegraph. Retrieved from http://www.telegraph.co. uk/technology/video-games/9593188/Violent-video -games-make-teenagers-more-aggressive-study-finds. html

We Are Müesli, \& Koning, A. (2015). SIHEYU4N. [Computer software]. Beijing: We Are Müesli.

Wenger, E. (1998). Communities of practice: Learning, meaning and identity. Cambridge: Cambridge University Press.

Wenger, E., McDermott, R., \& Snyder, W. M. (2002). Cultivating communities of practice. Boston, MA: Harvard Business School.

Wenger-Trayner, E., \& Wenger-Trayner, B. (2015). Learning in a landscape of practice: A framework. In E. Wenger-Trayner, M. Fenton-O'Creevy, S. Hutchinson, C. Kubiak, \& B. Wenger-Trayner (Eds.), Learning in landscapes of practice: Boundaries, identity and knowledgeability in practice-based learning (pp. 13-29). London: Routledge.

Wenger-Trayner, E., Fenton-O'Creevy, M., Hutchinson, S., Kubiak, C., \& Wenger-Trayner, B. (2015). Learning in landscapes of practice: Boundaries, identity and knowledgeability in practice-based learning. London: Routledge.

White, G., \& Parker, L. (in press). Video games in the museum: Participation, possibility and play in curating meaningful visitor experiences. Leonardo Electronic Almanac.

Wood, W. Z. (2016). Games beyond the screen: Festivals of play across the western world. In K. Duncan Valentine \& L. J. Jensen (Eds.), Examining the evolution of gaming and its Impact on social, cultural, and political perspectives (pp. 377-396). Hershey, PA: Information Science Reference.

YMPT Ltd. (2017). Feral vector. Retrieved from http:// feral-vector.com

\section{About the Author}

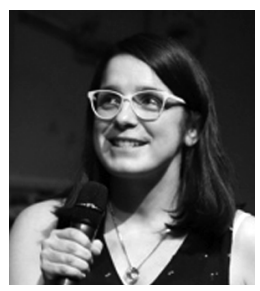

Lynn H. C. Love is a lecturer in Games and Arts in the School of Design and Informatics at Abertay University in Dundee, UK, where she teaches interactive arts, media design and animation. Lynn is a practicing designer and animator, having co-created interactive games, performances and events which fuse digital media and the physical world. Lynn recently successfully defended her PhD by Publication thesis which focusses upon the design of participation in social play to bring people together and potentially enact participant-led transformation. 